\title{
Evaluation of hepatic flow changes in early stages after extended hepatectomy by contrast enhanced ultrasound
}

\author{
N Fard", N Rezaei, G Emmami, A Saffari, M Golriz, A Mehrabi, H-P Schlemmer, S Delorme \\ From International Cancer Imaging Society (ICIS) 14th Annual Teaching Course \\ Heidelberg, Germany. 9-11 October 2014
}

\section{Background}

Extended hepatectomy (EH) is the only curative procedure in patients with large or multi-nodular liver tumours. However, the alterations of the hepatic inflow (HF) after $\mathrm{EH}$ and the consequent complications like "small for size syndrome" (SFSS) are still challenging issues. Contrastenhanced ultrasound (CEUS) is a non-invasive approach to evaluate liver haemodynamics with the advantages of imaging very low blood flow rates at the tissue perfusion level. The aim of this study is to detect the haemodynamic alterations after EH in early stage by CEUS in an experimental setting.

\section{Method}

An in vivo procaine model was studied using a low mechanical index in conjunction with single-level dynamic CEUS. A sulfur hexafluoride contrast agent (SonoVue; Bracco SpA, Milan, Italy) was applied in 5 pigs by intravenous bolus injection. Data were acquired before and after up to $75 \%$ sequential liver resections. Corresponding parameters of the time-intensity curve were measured using wash-in/wash-out curve software (Vuebox; Bracco SpA, Milan, Italy).

\section{Result}

Following sequential liver resection, the total HF increased gradually. In detail, the hepatic artery flow decreased $17 \%$ and portal vein flow increased around $70 \%$ after extended liver resection (75\%). Also, with sequential liver resection, the PVP increased gradually up to $33 \%$ after extended liver resection (75\%).

\footnotetext{
* Correspondence: n.fard@dkfz-heidelberg.de

German Cancer Research Center, Department of Surgery, Heidelberg

\section{Conclusion}

Quantitative and qualitative measurement of THF alteration in early stages is feasible by CEUS. CEUS is a suitable modality for follow-up control after $\mathrm{EH}$ in order to prevent postoperative complications such as SFSS, which lead to liver failure.

Published: 9 October 2014

doi:10.1186/1470-7330-14-S1-P35

Cite this article as: Fard et al.: Evaluation of hepatic flow changes in early stages after extended hepatectomy by contrast enhanced ultrasound. Cancer Imaging 2014 14(Suppl 1):P35.

Submit your next manuscript to BioMed Central and take full advantage of:

- Convenient online submission

- Thorough peer review

- No space constraints or color figure charges

- Immediate publication on acceptance

- Inclusion in PubMed, CAS, Scopus and Google Scholar

- Research which is freely available for redistribution

Submit your manuscript at www.biomedcentral.com/submit
() Biomed Central

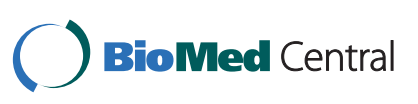

